\title{
ESTUDO SOBRE O DIAGNÓSTICO DA GIARDÍASE POR MEIO DO MÉTODO KATO-KATZ
}

\author{
Vera Lucia Pagliusi Castilho, Elaine Guizelini, Eliana Salgado \\ Turri, Vicente Amato Neto, Rubens Campos, Antonio \\ Augusto Baillot Moreira e Pedro Luiz Silva Pinto
}

\begin{abstract}
Foi verificado que é possivel diagnosticar a giardíase através de exame de fezes realizado pelo método de Kato-Katz, hoje bastante utilizado no Brasil. Todavia, para reconhecimento da protozoose em questão, a eficácia do processo da centrífugo-flutuação em sulfato de zinco mostrou-se maior. As sensibilidades das técnicas de Kato-Katz e da sedimentação espontânea em água foram equiparáveis, afigurando-se mais produtivas, a propósito do emprego da primeira, as análises efetuadas imediatamente ou após 24 horas em relação à ocasião do preparo.
\end{abstract}

Palavras chaves: Diagnóstico da giardiase. Exame parasitológico das fezes. Método de Kato-Katz.

Os indivíduos parasitados por Giardia lamblia eliminam diariamente, pelas fezes, grande quantidade de cistos desse protozoário e, por isso, o diagnóstico da giardíase pelo exame da matéria fecal torna-se em geral fácil, principalmente quando utilizados métodos de concentração, como o da centrífugo-flutuação em sulfato de zinco.

Cada vez com maior freqüência o processo de Kato-Katz está fazendo parte das atividades rotineiras de laboratórios de análises clínicas, para demonstrar ovos de Schistosoma mansoni e de outros helmintos, sendo a propósito encarado como merecedor de grande confiabilidade. No entanto, quanto à demonstração de cistos de protozoários existe certa controvérsia, pois muitos pesquisadores argumentam que a glicerina usada em uma das fases da sequiencia tática, relativa ao método em questão, agindo sobre a delicada membrana cística, clarifica-a, fazendo com que não seja visível o parasita. Existem, porém, referências sobre o encontro de oocistos de Isospora e de cistos de Giar-

Trabalho do Laboratório de Investigação Médica - Parasitologia, do Hospital das Clínicas, da Faculdade de Medicina da Universidade de São Paulo.

Endereço para correspondência: Laboratório de Investigação Médica - Parasitologia, Avenida Doutor Arnaldo 455, CEP 01246, São Paulo, Brasil.

Recebido para publicação em 16-5-83. dia lamblia e Entamoeba coli, quando usado tal procedimento ${ }^{2}$.

Como adquirimos razoável experiência à execução de diversas técnicas para exame parasitológico das fezes e considerando que a giardiase faz parte de nossas atuações costumeiras, resolvemos verificar especificamente a possibilidade de visualização da Giardia lamblia através da técnica de Kato-Katz. Paralelamente, julgamos também conveniente comparar a sensibilidade dela, no que se refere ao mesmo enfoque, diante de outros processos de enriquecimento, para cistos.

\section{MATERIAL E MÉTODOS}

Foram examinadas 150 amostras de fezes enviadas ao Laboratório Central do Hospital das Clínicas, da Faculdade de Medicina da Universidade de São Paulo. Cinqüenta continham certamente cistos de Giardia lamblia e iguais números de outras não haviam sido examinadas ou eram provenientes de comunidade com maior probabilidade de infecção pelo protozoário, abrangendo crianças com três a sete anos de idade.

Analisamos todos os materiais concomitantemente pelas técnicas de centrífugo-flutuação no sulfato de zinco (Faust e cols.), de sedimentação 
espontânea em água (Hoffman, Pons e Janer) e de Kato-Katz, seguindo as determinações originais, descritas em compêndio especializado'. Todavia, introduzimos alguns acréscimos ou etapas suplementares no que tange ao último, pois praticamos apreciações imediatas, após uma hora, como prevê o roteiro habitual, e depois de 24 horas, conservando para esta derradeira etapa as lâminas em câmara úmida. Recorremos sempre a aumento de $400 x$, observando apenas as bordas, nas quais ficam mais facilmente visualizados os cistos.

\section{RESULTADOS}

Nossas constatações principais figuram nos três itens em prosseguimento expostos.

A) Porcentagens de positividades relativas a 50 amostras de fezes que continham certamente cistos de Giardia lamblia (comparação entre o método da centrífugo-flutuação no sulfato de zinco e três variantes do processo de Kato-Katz): centrífugo-flutuação em sulfato de zinco - 100\%; Kato-Katz (exame imediatamente após a preparação) - 90\%; Kato-Katz (exame uma hora após a preparação) - 82\%; Kato-Katz (exame 24 horas após a preparação; conservação em câmara úmida) $-88 \%$.

B) Porcentagens de positividades relativas às amostras de fezes nas quais foram encontrados cistos de Giardia lamblia (exames pelos métodos da centrífugo-flutuação pelo sulfato de zinco, da sedimentação espontânea em água e de Kato-Katz executado segundo três variantes): centrífugoflutuação em sulfato de zinco e sedimentação espontânea em água - 41\%; Kato-Katz (exame imediatamente após a preparação) $-33 \%$; Kato-Katz (exame uma hora após a preparação) - 30\%; Kato-Katz (exame 24 horas após a preparação; conservação em câmara úmida) $-33 \%$.

C) Porcentagens de positividades relativas a 50 amostras de fezes de crianças com três a sete anos de idade (comparação entre os métodos da centrífugo-flutuação pelo sulfato de zinco, da sedimentação espontânea em água e de Kato-Katz executado segundo três variantes): centrífugoflutuação no sulfato de zinco - $22 \%$; sedimentação espontânea em água - 12\%; Kato-Katz (exame imediatamente após a preparação) - 10\%; Kato-Katz (exame uma hora após a preparação)
- 8\%; Kato-Katz (exame 24 horas após a preparação; conservação em câmara úmida) $-12 \%$.

Ficou demonstrado que, através do método de Kato-Katz, podemos encontrar e reconhecer as formas císticas de Giardia lamblia, ou seus contornos, quando elas são abundantes nas fezes, pois aparecem facilmente nas bordas do preparado. Todavia mesmo à apreciação de amostras seguramente positivas não sucedeu $100 \%$ de positividade.

O momento recomendado regularmente para observação, por esse processo, corresponde a uma hora após a preparação; mais tarde, o ressecamento dificulta a visualização dos cistos, criando então evidente percalço. $O$ exame imediato, por sua vez, mostra retrações, com espaços claros entre o citoplasma e a membrana, resultando aspecto de duplo contorno limitante. A colocação da lâmina em câmara úmida, durante 24 horas, faz com que as estruturas císticas voltem a apresentar aspecto normal, permitindo a identificação.

A inspecção imediatamente após a preparação ou em seguida à conservação em câmara úmida por 24 horas propiciam um pouco maiores porcentagens de positividades, e a comparação dos resultados advindos da aplicação dos três métodos evidenciou superioridade do baseado na centrífugo-flutuação em sulfato de zinco, com menor sensibilidade da sedimentação espontânea em água e do meio proposto por Kato-Katz, que se afigura menos eficiente quando a pesquisa tem lugar uma hora depois do preparo.

\section{DISCUSSĀO}

$O$ intuito desta investigação de caráter eminentemente prático teve nexo com o esclarecimento da possibilidade do método de Kato-Katz, hoje bastante usado no Brasil, mormente em trabalhos diagnóstico-terapêuticos ligados à esquistossomose mansônica, revelar a existência da giardíase, através do exame das fezes. Sentimos que a elucidação desse detalhe merecia atenção, em termos especulativos e operacionais, no amplo contexto das parasitoses intestinais.

Depois do estudo levado a cabo, estipulamos dedução agora valorizável em determinações laboratoriais rotineiras, configurada pela certeza de que a técnica de Kato-Katz está capacitada a mos- 
Castilho VLP. Quizelime, Turri ES, Amato Neto V, Campos R, Moreira AAB, Pinto PLS. Estudo sobre o diagnóstico da girdiase por meio de Kato-Katz. Revista da Sociedade Brasileira de Medicina Tropical 16:104-106, Abr-Jun, 1983

trar cistos de Giardia-lamblia, tendo para isso sensibilidade menor que a da centrífugo-flutuação em sulfato de zinco e semelhante à da sedimentação espontânea em água; não obstante, ela deve de preferência suscitar, para gerar maior efetividade, análises imediatamente ou após 24 horas, em relação à ocasião do preparo.

\section{SUMMARY}

The Kato-Katz technique for stool examination, now widely employed in Brazil, has been shown to be useful in the diagnosis of giardiasis. However, the efficacy of a concentration method, using zinc sulphate, was higher. The sensitivity of both the Kato-Katz technique and the gravity sedimentation method were compared and yielded similar results. As far as stool examination by the Kato-Katz technique are concerned, the best results were obtained after immediate analysis or 24 hours later.

Key words: Diagnosis of giardiasis. Stool examination. Kato-Katz technique.

\section{REFERENCIAS BIBLIOGRĀFICAS}

1. Amato Neto V, Corrêa LL. Exame parasitológico das fezes. Savier, São Paulo, 1980.

2. Pereira Júnior DB. Utilização do método KatoKatz para o diagnóstico de Isospora: resultados preliminares. In: Resumos do VI Congresso da Sociedade Brasileira de Parasitologia, Belo Horizonte, p. 30, 1980. 